\title{
PENINGKATAN PENGETAHUAN ORANG TUA SISWA SEKOLAH DASAR DENGAN WORKSHOP CYBER SAFETY
}

\section{INCREASING KNOWLEDGE OF ELEMENTARY SCHOOL STUDENT PARENTS WITH CYBER SAFETY WORKSHOP}

\author{
Yahya Thamrin, ${ }^{1}$ Atjo Wahyu, ${ }^{1}$ Furqaan Naeim, ${ }^{1}$ Iin Karmila Yusri, ${ }^{2}$ Andi Hardianti ${ }^{3}$ \\ ${ }^{1}$ Bagian Kesehatan dan Keselamatan Kerja, Fakultas Kesehatan Masyarakat Universitas \\ Hasanuddin, Makassar \\ ${ }^{2}$ Program Studi Teknik Komputer dan Jaringan, Politeknik Negeri Ujung Pandang, Makassar \\ ${ }^{3}$ Bagian Epidemiologi, Fakultas Kesehatan Masyarakat, Universitas Hasanuddin,
} Makassar

Alamat Korespondensi: Fakultas Kesehatan Masyarakat Universitas Hasanuddin, Makassar, 90245 HP: +6281341506959, Email: yahyathamrin@yahoo.com

\begin{abstract}
Abstrak
Saat ini gadget dan internet awalnya digunakan sebagai alat dan media komunikasi untuk mempermudah dan membantu manusia pada berbagai jenis sektor kehidupan seperti ekonomi, hiburan dan pendidikan. Tujuan dari penelitian ini untuk mengetahui perbedaan pengetahuan sebelum dan setelah kegiatan workshop dilakukan. Kegiatan dilakukan di dua sekolah dasar di Kota Makassar, SD Darussalam dan SDN PAI Kota Makassar. Sampel berjumlah 60 orang tua siswa pada dua sekolah dasar dengan masing-masing 30 orang tua siswa di tiap sekolah dasar. Data dianalisis menggunakan uji T. Hasil analisis menunjukkan ada perubahan pengetahuan sebelum dan sesudah workshop di dapatkan hasil $\mathrm{p}=0,000$. Pemberian edukasi melalui workshop menurut hasil analisis berpengaruh pada peningkatan pengetahuan orang ttua siswa. diharapkan agar orang tua, sekolah dan pemerintah setempat dapat bekerja sama dalam meningkatakan awareness cyber safety ini dan mengurangi risiko-risiko yang membahayakan kesehatan dan keselamatan.
\end{abstract}

Kata kunci: Cyber Safety, Pengetahuan

\begin{abstract}
Recently, gadgets and the internet are used as tools to communicate online that ease people in various ways of human life's sectors such as economy, entertainment and education. The aims of this study was to determine difference in knowledge before and after the workshop activities. The activity was carried out in two elementary schools in Makassar City, SD Darussalam and SDN PAI Makassar City. The sample consisted of 60 parents of students in two elementary schools with 30 parents each in each elementary school. Data were analyzed using the T test. The results of the analysis showed that there was a change in knowledge before and after the workshop that the results obtained $p=0,000$. Provision of education through workshops according to the results of the analysis has an effect on increasing the knowledge of students' parents. It is hoped that parents, schools and local government can work together to increase cyber safety awareness and reduce risks that endanger health and safety.
\end{abstract}

Keywords: Cyber safety, Knowledge 


\section{PENDAHULUAN}

Seperti diseluruh dunia, perkembangan teknologi di Indonesia juga sangat pesat diikuti oleh berbagai jenis gadget yang tersedia. Gadget dan internet awalnya digunakan sebagai media untuk mempermudah dan membantu berbagai jenis sektor kehidupan seperti ekonomi, hiburan dan pendidikan. Namun, saat ini gadget dan internet sangat mudah diakses oleh anak-anak dalam frekuensi yang sangat sering. Pengguna internet di Indonesia terbanyak berusia 35-44 tahun (29.2\%), kemudian usia 25-34 tahun (24.4\%), 10-24 tahun (18.4\%), 45-54 tahun (18\%), dan 55 tahun ke atas (10\%) (APJII, 2017). Namun menurut APJII (2017), kelompok usia 10 24 tahun merupakan kelompok usia dengan intensitas penggunaan internet paling tinggi $(75.5 \%)$.

Di Kota Makassar, kelompok usia 10-24 tahun mencakup $32.11 \%$ dari total penduduk di Tahun 2016 dan sebagian besar mereka adalah pelajar dan mahasiswa (BPS Kota Makassar, 2017). Hampir semua pelajar dan mahasiswa memiliki telepon selular dengan fasilitas akses internet, dan menurut Kemp (2015) mayoritas penduduk di Indonesia mengakses internet melalu telepon selular mereka.

Salah satu antisipasi untuk melindungi kelompok usia muda dari dampak buruk internet yang dilakukan oleh
Pemerintah Kotamadya Makassar adalah mengeluarkan perintah kepada semua sekolah di lingkup Kota Makassar untuk mengawasi penggunaan smartphone di sekolah (Berita-Sulsel, 2017). Namun pengawasan disekolah tidaklah cukup karena menurut BPS Kota Makassar (2017) hanya $31.63 \%$ kelompok usia pelajar dan mahasiswa mengakses internet di sekolah, sekitar $89.36 \%$ pelajar dan mahasiswa di Kota Makassar melakukan koneksi internet di rumah sendiri. Sehingga orang tua mempunyai peranan yang paling penting untuk secara aktif melindungi anak-anak mereka dari bahaya internet.

Selain mempengaruhi kesehatan fisik, Internet juga berpengaruh negatif pada kesehatan mental. Pertama, rusaknya pola pergaulan sosial. Pengguna internet yang sudah mulai ketagihan berinternet cenderung akan menghabiskan waktunya untuk internet daripada bermain dengan teman sebayanya. Pengaruh negatif lainnya adalah malas belajar. Pengguna internet dengan intensitas tinggi cenderung akan malas belajar. Mereka akan sulit menerima materi pelajaran karena pikiran tidak bisa fokus pada pelajaran.

Bukan hanya memberikan pengaruh negatif pada kesehatan, internet juga berpengaruh pada keselamatan penggunanya. Bully di media sosial, 
kecanduan pornografi, dan pelecahan seksual akibat menjamurnya konten-konten yang berbau pornografi dan kekerasan yang mempengaruhi tingkah laku mereka. Juga terbukanya berbagai informasi pribadi pengguna internet menjadikan mereka sasaran mudah untuk kejahatan. Pengguna internet usia dini juga sering menjadi target doktrinisasi kelompok tertentu yang bertujuan untuk merekrut anggota baru kelompok mereka. Mereka mempenetrasikan doktrin mereka melalui berita, permainan, dan situs hiburan yang dapat dengan mudah diakses oleh pengguna internet usia muda.

Orang tua semakin khawatir dengan dampak negative dari anak-anak yang terlalu sering terpapar dengan gadget dan internet. Maka dengan kegiatan workshop dengan orang tua murid ini ingin diketahui apakah ada perubahan pengetahuan sebelum dan setelah kegiatan workshop dilakukan.

\section{METODE}

\section{Lokasi}

Kegiatan dilakukan di dua sekolah dasar di Kota Makassar, SD Darussalam dan SDN PAI Kota Makassar.

\section{Populasi dan sampel}

Sampel berjumlah 60 orang tua siswa pada dua sekolah dasar dengan masingmasing 30 orang tua siswa di tiap sekolah dasar.

\section{Metode pengumpulan data}

Pengumpulan data dilakukan dengan kuesioner yang diberikan sebelum workshop dan sesudah workshop pada orang tua siswa dengan rancangan pre-post test design.

\section{Analisis data}

Analisis data dilakukan dengan menggunakan program SPSS untuk melihat apakah ada perbedaan sebelum dan sesudah workshop dilakukan. Analisis juga dilakukan untuk melihat apakah ada perubahan pengetahuan yang terjadi pada orang tua siswa.

\section{HASIL}

Untuk melihat apakah ada perubahan pengetahuan sebelum dan sesudah workshop mengenai cyber safety pada orang tua digunakan kuesioner pre dan post test. Hasil yang didapatkan bahwa mayoritas dari sampel adalah perempuan. Selain itu pekerjaan dari para responden yaitu tidak bekerja 18,3\%, Ibu Rumah Tangga 76,7\% dan sisanya adalah sebagai Pegawai Negeri Sipil (PNS) 3,3\% dan Karyawan Swasta 1,7\% (Tabel 1).

Sedangkan untuk pendidikan responden yang paling banyak adalah SMA dengan 45,0 \% kemudian S1 sebanyak 36,7 $\%, 16,7 \%$ dengan pendidikan D3 dan 1,7\% dengan pendidikan S2 (Tabel 2). 
Tabel 1. Frekuensi Jenis Pekerjaan Orang Tua Siswa

\begin{tabular}{lcc}
\hline \multicolumn{1}{c}{ Pekerjaan } & n & \% \\
\hline Tdk bekerja & 11 & 18,3 \\
IRT & 46 & 76,7 \\
PNS & 2 & 3,3 \\
Karyawan Swasta & 1 & 1,7 \\
\hline Total & $\mathbf{6 0}$ & $\mathbf{1 0 0 , 0}$ \\
\hline
\end{tabular}

Tabel 2. Frekuensi Pendidikan Terakhir Orang Tua Siswa

\begin{tabular}{ccc}
\hline Pendidikan & n & \% \\
\hline SMA & 27 & 45,0 \\
D3 & 10 & 16,7 \\
S1 & 22 & 36,7 \\
S2 & 1 & 1,7 \\
\hline Total & $\mathbf{6 0}$ & $\mathbf{1 0 0 , 0}$ \\
\hline
\end{tabular}

Kemudian untuk melihat ada perubahan perubahan peningkatan pengetahuan pengetahuan sebelum dan sesudah sebelum dan sesudah workshop dilakukan workshop di dapatkan hasil $\mathrm{p}=0,000$. Nilai $\quad$ (Tabel 3). tersebut menunjukkan bahwa benar ada

Tabel 3. Uji Beda Pre-Post Test Workshop Cyber Crime

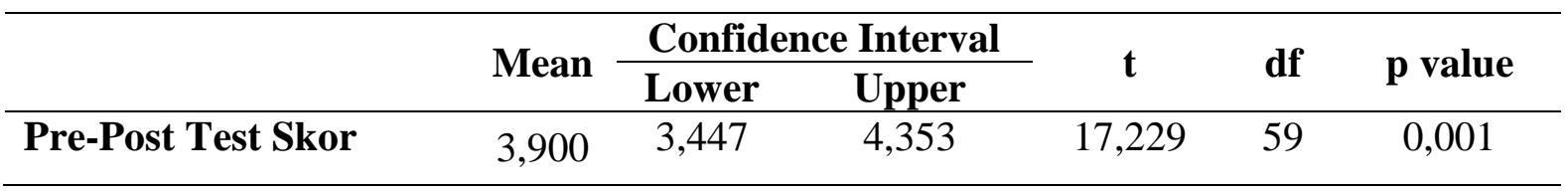

\section{PEMBAHASAN}

Melihat hasil yang menunjukkan bahwa ada perubahan pengetahuan sebelum dan sesudah workshop cyber safety pada orang tua siswa. Hal ini menunjukkan bahwa workshop yang dilakukan melalui edukasi dan pemberian tips dan trik menggunakan gadget dan teknologi bagi anak-anak usia sekolah dapat meningkatkan pengetahuan. Materi diberikan dengan metode ceramah yang memungkinkan terjadinya komunikasi dua arah, dari pemateri maupun responden. Metode ini berlangsung dengan tatap muka sehingga memungkinkan terjadinya diskusi mengenai topik tersebut.

Hasil yang menunjukkan adanya perbedaan pengetahuan sebelum dan setelah workshop dengan $p$ value $=0,001$. Pemberian edukasi melalui workshop menurut hasil analisis berpengaruh pada peningkatan pengetahuan orang ttua siswa. 
Edukasi merupakan salah satu cara untuk memperoleh pengetahuan yang akan mendasari sikap dan perilaku manusia. Handayani (2007) dalam penelitiannya, bahwa adanya pengetahuan tentang manfaat sesuatu hal dapat mempengaruhi niat untuk ikut dalam suatu kegiatan. Seperti halnya edukasi cyber safety yang dilakukan pada orang tua siswa ini akan mempengaruhi pola asuh orang tua pada anak-anak mereka yang menggunakan gadget dan teknologi.

Peningkatan pengetahuan terjadi diasumsikan peneliti karena adanya keterlibatan responden dalam proses workshop secara aktif dengan cara diskusi, sharing yang meningkatkan minat dan kesadaran responden. Selain itu, pemberian informasi dikaitkan dengan kondisi yang dialami orang tua saat ini serta penggunaan bahasa yang mudah dimengerti oleh para orang tua siswa.

Pengetahuan adalah hasil pengindraan manusia atau hasil tahu seseorang terhadap objek. Dengan sendirinya pada waktu penginderaan sampai menghasilkan pengetahuan tersebut sangat dipengaruhi oleh intensitas perhatian dan persepsi terhadap objek (Notoatmodjo, 2010). Penginderaan melalui penglihatan, pendengaran, penciuman, rasa, dan raba. Pengetahuan merupakan domain yang sangat penting dalam membentuk perilaku seseorang. Berdasarkan pengalaman dan penelitian terbukti bahwa perilaku yang didasari oleh pengetahuan akan lebih langgeng dari pada perilaku yang tidak didasari oleh pengetahuan (Notoadmodjo, 2010).

Oleh karena itu materi workshop yang diberikan merupakan sebuah upaya untuk meningkatakan awareness para orang tua siswa tentang cyber safety. Cyber safety sendiri adalah sebuah konsep keamanan dalam menggunakan internet, gadget dan teknologi agar mengurangi risiko-risiko yang dapat terjadi dalam menggunakan internet dan gadget. Risiko-risiko tersebut sangat luas yaitu risiko yang menggangu kesehatan dan keselamatan. Risiko yang cukup mengkhawatirkan bagi orang tua saat ini antara lain merusak kesehatan mata, cyber bullying, identitas yang bocor, penipuan via online, kecanduan bermain game, anti social, hingga gangguan mental.

Hasil wawancara mengemukakan bahwa orang tua mengetahui bahwa anakanak mereka menggunakan untuk internet mayoritas untuk nonton youtube dan bermain game. Namun, tentu sulit untuk memastikan bahwa anak-anak tersebut tidak akan terpapar hal-hal negative dari internet. Sehingga peran orang tua sangat penting, untuk mengawasi anak-anak mereka tentu saja diperlukan pengetahuan yang mumpuni mengenai cyber safety, bagaimana memanfaatkan teknologi secara positif dan aplikasi yang dapat membantu 
orang tua mengawasi aktivitas internet anak-anak mereka.

Bukan hanya memberikan pengaruh negatif pada kesehatan, internet juga berpengaruh pada keselamatan penggunanya. Bully di media sosial, kecanduan pornografi, dan pelecahan seksual akibat menjamurnya konten-konten yang berbau pornografi dan kekerasan yang mempengaruhi tingkah laku mereka. Juga terbukanya berbagai informasi pribadi pengguna internet menjadikan mereka sasaran mudah untuk kejahatan. Pengguna internet usia dini juga sering menjadi target doktrinisasi kelompok tertentu yang bertujuan untuk merekrut anggota baru kelompok mereka. Mereka mempenetrasikan doktrin mereka melalui berita, permainan, dan situs hiburan yang dapat dengan mudah diakses oleh pengguna internet usia muda.

Lebih lanjut dari hasil wawancara diketahui bahwa dari pihak sekolah pun tidak memiliki peraturan yang mengatur bagaimana seorang siswa menggunakan gadget dan teknologi. Hal ini sesuai dengan hasil yang didapatkan di Afrika oleh Kritzinger (2015) bahwa tidak ada komitmen untuk mengimplementasikan pendidikan cyber safety dalam kurikulum sekolah. Sekolah saat ini tidak dilengkapi dengan sarana yang mendukung cyber safety. Perlu diperhatikan agar sekolah juga turut memberi pendidikan cyber safety pada anak-anak usia sekolah karena lingkungan sekolah sangat berpengaruh pada usia sekolah.

Pengetahuan mengenai cyber safety sangat perlu untuk orang tua di era milenial saat ini. Teknologi terus berkembang dan kita perlu mengetahui perkembangan dunia agar tidak tertinggal. Namun, tentu teknologi mempunyai sisi positif dan negative terutama bagi anakanak usia sekolah. Tugas orang tua yaitu mendampingi, mengawasi dan mengarahkan anak-anak bagaimana agar tidak terjadi hal-hal yang dapat merugikan.

Oleh karena itu, dilakukan workshop pada orang tua siswa terkait cyber safety dengan metode ceramah dan tanya jawab. Untuk itu kami ingin melihat apakah ada peningkatan pengetahuan orang tua siswa sebelum dan sesudah dilakukannya workshop. Hasil yang didapatkan menunjukkan adanya pengingkatan pengetahuan orang tua siswa megenai cyber safety.

\section{KESIMPULAN DAN SARAN}

Kesadaran terkait saat ini sangat penting bagi setiap orang termasuk orang tua. Hasil uji T menunjukkan $p$ value $=0,001$ yang menunjukkan adanya peningkatan pengetahuan orang tua siswa sebelum dan sesudah diberikan edukasi melalui workshop. Mengetahui beberapa kekurangan dalam penelitian ini diharapkan agar dilakukannya penelitian yang lebih 
koperehensif terhadap cyber safety pada orang tua dengan melihat variable-variabel yang belum dinilai dalam penelitian ini. Selain itu, diharapkan agar orang tua, sekolah dan pemerintah setempat dapat

\section{DAFTAR PUSTAKA}

APJII. (2017). Infografis: Penetrasi \& Perilaku Pengguna Internet Indonesia; Survey 2016. Assosiasi Penyelenggara jasa Internet Indonesia (APJII). Polling Indonesia Kritzinger, E., 2015, July. Enhancing cyber safety awareness among school children in South

Africa through gaming. In 2015 Science and Information Conference (SAI) (pp.1243-1248). IEEE.

Handayani, Sri., Emilia, Ova,. (2009). Efektifitas Metode Diskusi Kelompok Dengan dan Tanpa Fasilitator Pada Peningkatan Pengetahuan, Sikap dan Motivasi Remaja Tentang Perilaku Seks bekerja sama dalam meningkatakan awareness cyber safety ini dan mengurangi risiko-risiko yang membahayakan kesehatan dan keselamatan.

Pranikah. Berita Kedokteran Masyarakat, Vol. 25 No 3 hlm 133141

BPS Kota Makassar. (2017). Statistik Kesejahteraan Rakyat Kota Makassar 2016. Katalog: 4101002.7371

Kemp, S. (2015). Digital, social and Mobile in 2015: We are social's compendium of global digital statistics: We are social.

Notoatmodjo, Soekijo. 2010. Ilmu Perilaku Kesehatan. Jakarta: Rineka Cipta.

Berita Sulsel. (2017). Sekolah di Makassar Wajib Awasi Penggunaan Smartphone. http://beritasulsel.com/2017/03/sekolahmakassar-wajib-awasi-penggunaansmartphone/diunduh 27 Juni 2017 